\title{
SUPPORTING ADDITIVE MANUFACTURING TECHNOLOGY DEVELOPMENT THROUGH CONSTRAINT MODELLING IN EARLY CONCEPTUAL DESIGN: A SATELLITE PROPULSION CASE STUDY
}

\author{
O. Borgue ${ }^{1, \bigotimes}, \mathrm{F}$. Valjak ${ }^{2}$, M. Panarotto ${ }^{1}$ and 0 . Isaksson ${ }^{1}$ \\ ${ }^{1}$ Chalmers University of Technology, Sweden, ${ }^{2}$ University of Zagreb, Croatia \\ $\triangle$ borgue@chalmers.se
}

\begin{abstract}
Function and constraints modelling are implemented to design two gridded ion thrusters for additive manufacturing (AM). One concept takes advantage of AM design freedom, disregarding AM limitations and is not feasible. The other concept considers AM limitations and is manufacturable and feasible. Constraints modelling highlights AM capabilities that can be improved, showing where future investment is needed. Constraints representation can also support the creation of technology development roadmaps able to identify areas of AM technologies that must be improved.
\end{abstract}

Keywords: additive manufacturing, architectural design, technology development

\section{Introduction}

Successful products need principally to satisfy user and customer expectations, often articulated as required functions, while ensuring efficient manufacturing. A proper assessment of product manufacturability requires a clear understanding of the manufacturing capabilities and constraints and its impact on product design. However, design decisions regarding trade-offs between manufacturability and user expectations are usually taken in early design phases. Namely, the early design phases include the stages, as defined by Pahl et al. (2007), of planning, conceptual design and first steps of embodiment design until the preliminary layout is established. Therefore, the "implications" of decisions made in such early phases cannot be completely assessed as the product is not completely defined (Lu and Liu, 2011).

In this context, Additive manufacturing (AM) is a relatively new manufacturing technology that is making its way into various industrial applications. Due to the promised design freedom and "complexity for free" (Diegel et al., 2019), AM potentially enables weight, lead-times and unit cost reduction. Despite these promised benefits, AM comes with manufacturing constraints that limit design freedom and reduce the possibility of achieving novel AM geometries that can be produced in a costefficient manner (Borgue et al., 2019). There is a trade-off between satisfying customers' expectations on functionality and performance with the manufacturer's perspective of competitive and cost-efficient development and manufacturing.

Such trade-offs are currently very visible in industries characterized by long and costly development efforts which at the same time are undergoing radical changes in the way of doing business. For example, manufacturers of space products such as satellites have had a strong focus on increasing the performance of their products, with governmental programs as unique buyers of a few 'one off' systems. The emergence of more entrepreneurial actors is driving new business scenarios in the space industry - 
such as the development of mega constellations for worldwide internet coverage (Öhrwall Rönnbäck and Isaksson, 2018) which already anticipates a significant increase in production volumes. In this new scenario, expectations on product performances can be underemphasized in favour of weight unit cost reduction, which makes AM an attractive technology (Diegel et al., 2019). However, this increase in production volumes increased the emphasis of manufacturability and development efficiency during the design of space systems, since they are sources of hidden costs and revenue losses (Öhrwall Rönnbäck and Isaksson, 2018). However, when implementing AM for space components, there is a lack of experience and a large number of uncertainties and unknowns associated with manufacturing limitations and feasibility (Diegel et al., 2019). Due to the promised AM design freedom, design for AM methods (DfAM) can sometimes produce designs that are impossible to manufacture because of current AM constraints. As AM technology is developed, through long and costly research endeavours, AM constraints are "relaxed" and designs that were unfeasible before, can become manufacturable.

There are in literature different DfAM methods that can produce feasible AM design (methods usually based in considering AM limitations) and methods that can sometimes produce unfeasible designs (as they do not consider AM limitations). However, there is little research concerned with the process of rendering an unfeasible AM concept, feasible through planned technology development. When conceptualizing product architectures today that should be able to evolve into future, currently unfeasible, architectures (as is the case when developing technology roadmaps), engineers are left with little tools. This lack of tools has a great effect in decision making for technology investments, especially in highly technological products, such as space products. As technologies for space applications are costly to develop, concrete knowledge about which technology to develop and when, can provide great competitive advantage. This paper addresses the problem of how to implement the knowledge available in early design phases for decision making about what innovative technology to select for further architecture development.

Therefore, this study has focused on the following research question:

\section{$R Q-H o w$ can decisions about additive manufacturing technology development be supported in early conceptual design?}

\section{Background \& related work}

Several different scales, such as technology readiness level (TRL), have been developed to assess technology maturation and support its development. These scales support cost balancing activities and schedule planning or risk management (Conrow, 2011; Williamson and Beasley, 2011). A literature review reported by Conrow (2011) states that several attempts to relate TRL values to cost growth and schedule planning have been made for aerospace programs. However, those attempts are mostly subjective, as the TRL of a technology is determined based on experts' opinion (Sarfaraz et al., 2012). The topic of technology development related with architecture development is largely touched upon in literature about technology roadmaps. Literature reviews about technology roadmaps performed by authors such as de Alcantara and Martens (2019) or Gerdsri et al. (2013) analysed, together, almost 400 articles from 1985 to 2018 . According to those reviews, great efforts are set in roadmaps implementation for technology selection. Authors such as Viola et al. (2020) state technology roadmap strategies should enable the establishment of incremental technology development paths to achieve defined target missions, correlated with cost and time budgets.

However, no reviewed article seems to present a clear link between the evolution of product architecture and the accompanying technology development. Researchers such as (Lai et al., 2019 or Viola et al., 2020) proposed analytical methods for technology development planning, selecting development projects and creating technology development paths subject to limited cost/time budgets. However, these methods do not relate technology development with architecture development; nor assesses the necessary technology development activities needed to evolve current, feasible, product architectures into future architectures (nowadays unfeasible).

On the last decades, several Design for Additive Manufacturing (DfAM) methodologies were developed. Some methodologies are focused mostly on manufacturing limitations (constraints-based), creating feasible designs (Thompson et al., 2016), and others are focused on disruptive designs (opportunity-based designs) that many times disregard manufacturability, creating unfeasible designs 
(Campbell et al., 2012; Boyard et al., 2013). Nevertheless, assessments about technology development activities to make an AM design feasible, are scarce in the literature. However, recent studies presented by authors such as Borgue et al. (2019) or Patterson and Allison (2019) suggest the possibility of mapping product manufacturing constraints to establish clear limits for a product design space. The drawback of these methods is that they focus on developing feasible concepts and not on how to render unfeasible concepts, feasible.

In this article, a constraint-based feasible AM design is compared with an unfeasible opportunitybased design. The comparison of their capabilities and manufacturing constraints leads to the proposal of a strategy to estimate cost and technology schedule development to be implemented in companies' $R \& D$ departments for rendering unfeasible designs, feasible. The presented study is illustrated with a case study featuring a gridded ion thruster for satellite applications.

\section{Method}

To link AM technology roadmaps strategies with product architecture designs function modelling (FM) techniques are implemented in this study. They are used to create two different AM designs: a constraints-based design manufacturable with current AM technologies; and an opportunity-based design that makes use of AM design freedom and AM technology ample capabilities but is unfeasible with current AM technologies. The design of both concepts is performed implementing the design method "Mapping of product function with design principles for AM" proposed by Valjak et al. (2018). This method was preferred as it allows an abstract representation of overall product architecture, enabling the development of radical AM products (Valjak et al., 2018).

In this article, the method used a function model created with Hirtz vocabulary of functions and flows (Hirtz et al., 2002). First, a product functional decomposition is performed, arranging functions and flows following Hirtz models (2002). Then, functions are mapped with AM design principles as proposed by (Valjak et al., 2018). From that standard (unconstrained) version of the Hirtz-based function model, an opportunity-based design is developed. The unconstrained FM is then enhanced with AM manufacturing constraints, to develop a constraints-based design. The comparison of both designs then leads to their positioning in different company development strategies and a reflection about technology development roadmaps for additive manufacturing.

The presented method is presented and summarized in Figure 1:

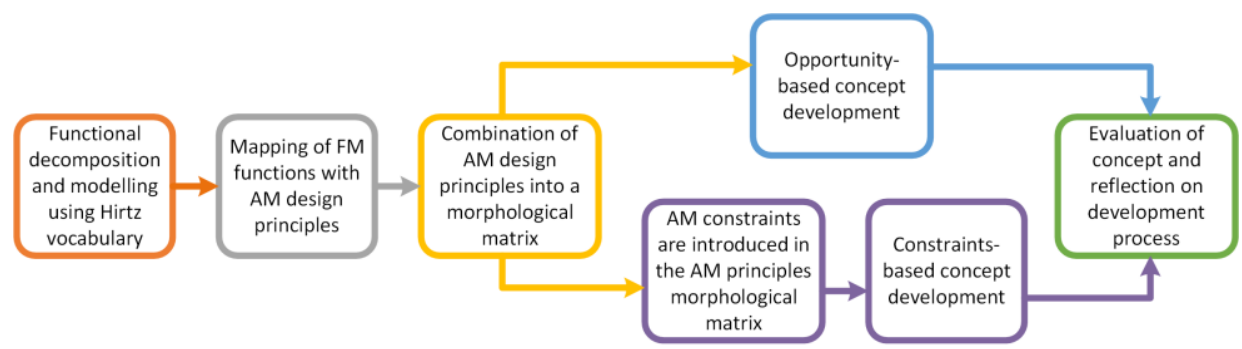

Figure 1. Method diagram

The two concepts developed implementing the proposed method were assessed by two industrial practitioners in the field of design for AM and two in the field of aerospace components design.

In this study, a Hirtz-based "Mapping of product function with design principles" method (Valjak et al., 2018) was chosen to develop the function model. However, other function modelling techniques such as those proposed by Weilkiens with SysML combined with UML (Weilkiens, 2007) or the function-behaviour-state model (Umeda et al., 1990) can be implemented.

\section{Case study}

Gridded ion thrusters (GIT) are low-thrust electric propulsion thrusters for spacecrafts (Figure 2). In these thrusters, a neutral gas (1), usually Xenon (Xe), is supplied from the fluid management system and introduced in an anode chamber (2) and ionized, bombarding it with energetic electrons (e-) provided by a cathode (3). Ionization efficiency is increased with the implementation of magnetic 
rings (4), which prolongs the path of the electrons to the exit, increasing their probability of collision with Xe atoms. The resultant positively charged ions are attracted towards the exit of the thruster with an array of metallic grids (5). The potential difference between the grids accelerates the ions, generating thrust for the spacecraft. In the end, the thruster emits a beam of positive Xe ions, which are then neutralized (to prevent charge accumulation on the spacecraft) with another cathode (6), usually placed outside the thruster body, that emits electrons into the ion beam.

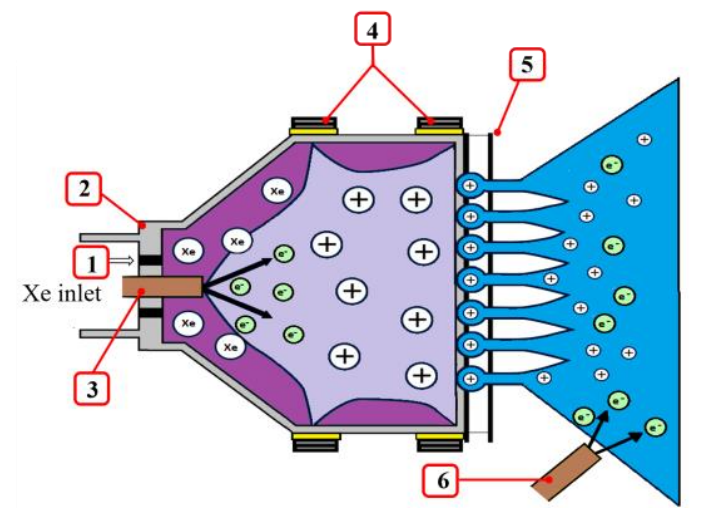

Figure 2. Gridded ion thruster (Kindberg, 2017; Hopping and Xu, 2017)

Due to their complex geometry and low-production volume, propulsion systems are good candidates to benefit from AM technologies (Hopping and $\mathrm{Xu}, 2017$ ). In this article, a mini GIT with a thrust force of a few $\mathrm{mN}$ is designed for AM. Mini GIT can provide thrust to satellites up to $100 \mathrm{~kg}$ and to perform almost any kind of altering manoeuvre for orbital position and attitude control (Kindberg, 2017). Usual GIT materials are indicated in Figure 2, the considered dimensions of the thruster are approximately 70mm in both height and diameter (Kindberg, 2017).

\section{Results}

\subsection{Function modelling and $A M$ principles mapping}

The development process of a gridded ion thruster started with the creation of a function model (FM), implementing Hirtz's vocabulary of functions and flows (Hirtz et al., 2002). The created FM consists of eighteen functions and connecting flows on a high level of abstraction, as presented in Figure 3. To facilitate the understanding of the model, concise explanations of ambiguous functions are included in parenthesis.

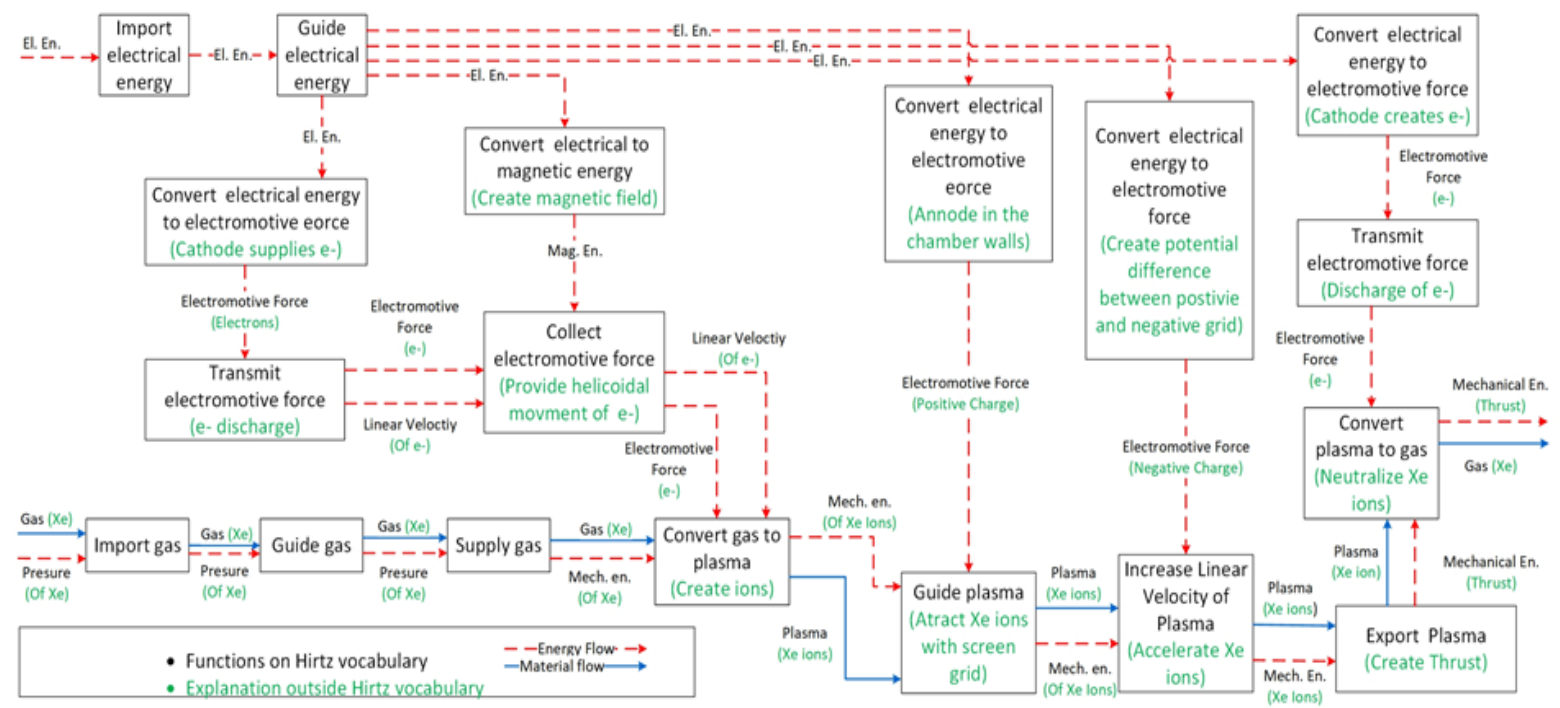

Figure 3. Hirtz et al. (2002) based GIT Function model 
After the creation of the FM, the model was analysed to match each function with possible AM capabilities (Diegel et al., 2019). Furthermore, the relative position of the functions and connecting flows were analysed to identify blocks of functions that can be integrated and solved with the same AM design principle. For example, the function "Import Gas" can be mapped with the principles "Adjust the geometry to fit existing interface" or "Embed a functional component". On the other hand, the block of functions "Import Gas", "Guide Gas" and "Supply Gas" can be integrated and mapped with principles "Use custom geometry to fit the use case" or "Embedded component". Part of the conducted mapping is presented in Table 1.

Table 1. Mapping of product function with design principles for AM (Valjak et al., 2018)

\begin{tabular}{|c|c|}
\hline Function & AM principles \\
\hline $\begin{array}{l}\text { Convert Elect. Energy to Electromotive Force \& Transmit } \\
\text { Electromotive Force \& Convert plasma to gas (cathodes) }\end{array}$ & Embed component/Multi-material structures. Customized geometry \\
\hline $\begin{array}{l}\text { Convert Electrical to Magnetic Energy \& Collect } \\
\text { electromotive force (electromagnets/magnets) }\end{array}$ & Embed component/Multi-material structures/Customized geometry \\
\hline Import Gas \& Guide gas (Fluid management system) & Embed component/ Customized geometry \\
\hline Supply Gas (Fluid management system-anode connection) & Embed component/Multi-material structures. \\
\hline Convert Elect. Energy to Electromotive Force (Anode) & Embed component/Multi-material structures/Customized geometry \\
\hline Guide Plasma \& Increase linear velocity of plasma (Grids) & Embed component/Multi-material structures/Customized geometry \\
\hline
\end{tabular}

\subsection{Opportunity-driven concept}

After mapping functions with design principles, a morphological matrix was built for developing different conceptual designs. In the development process, additional requirements such as light-weight and partconsolidation were considered together with the fulfilment of every product function. The opportunitydriven concept is presented in Figure 4.a. and consists of a consolidated thruster structure with an aluminium chamber (1) that embed all the other functional elements. The ability to produce complex shapes with AM enabled optimisation of the internal chamber to maximise thruster performance. The import of the propellant is achieved with an integrated connecting point (2), the guidance of the gas is enabled with internal channels (3) that do not require additional machining, while the shape of gas exit (4) is customised for better distribution of the propellant inside the chamber. The electrons source needed for plasma generation is a hollow cathode $(5,10)$, which is embedded during manufacturing, avoiding later assembly processes. Due to the possibility of using multi-materials during single a build, the electromagnets are fabricated inside the single body using copper for coil manufacturing (6) and iron for the core (7). The same multi-material principle is used for manufacturing an integrated wiring system thought the body, to guide electrical energy, as well as for manufacturing the thruster's exit grids $(8,9)$. Due to the same electrical potential first grid and chamber are made as a single unit.
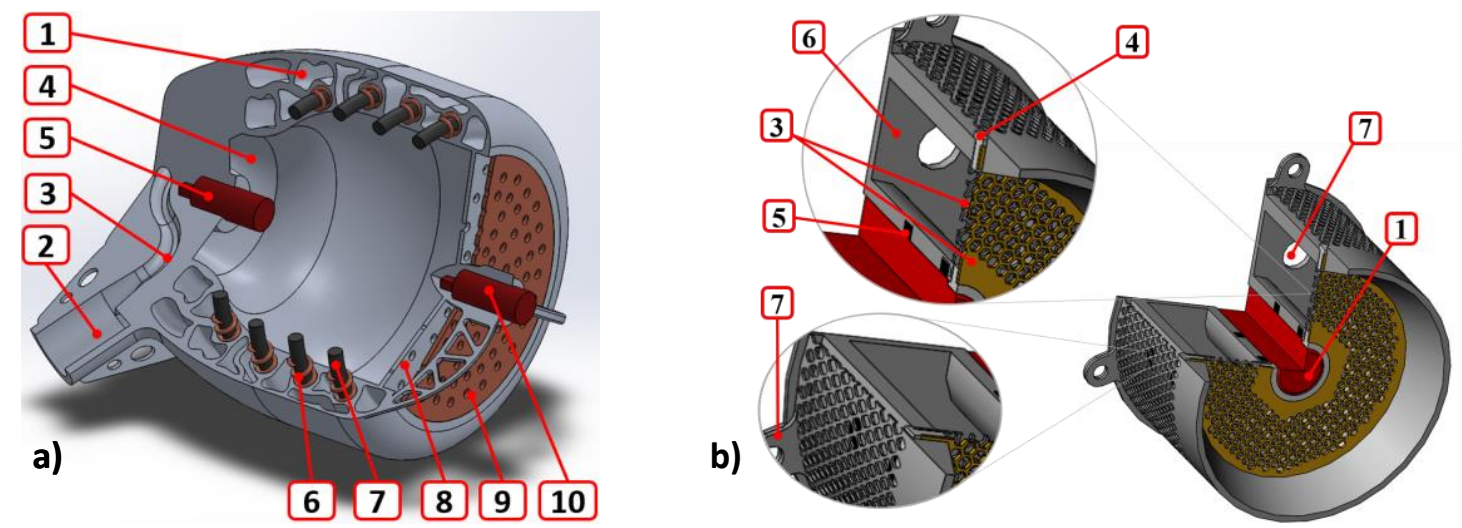

Figure 4. a) Opportunity-based and, b) Constraints-based AM design 


\subsection{Constraints-driven concept}

To develop the constraints-driven GIT concept, manufacturing constraints were applied to the AM principles in two steps. The first step applied general AM constraints such as material availability and TRL level of AM principles. However, as AM constraints are largely geometry dependent (Borgue et al., 2019), the second step of constraints identification was performed concurrently with the geometrical design. The implemented constraints are presented in Table 2. Due to the low TRL of AM technologies for printing materials such as samarium-cobalt, for permanent magnets, these materials were not considered for GIT AM components (Diegel et al., 2019), however, there are nowadays promising commercial applications for high quality AM electromagnets (Nano Dimension, 2019). AM embedded components and multi-material technologies are gaining popularity in electronic applications, however, their implementation in other industries is still immature, for this reason, embedded components and multi-material structures were disregarded for mechanical GIT components (Diegel et al., 2019).

Table 2. Constraints limiting the implementation of $A M$ principles and $A M$ design

\begin{tabular}{|c|c|c|c|}
\hline Function & AM principles & Opportunity-based concept constraints & $\begin{array}{l}\text { Constraints-based } \\
\text { concept constraints }\end{array}$ \\
\hline $\begin{array}{l}\text { Convert Elect. Energy to Electromotive } \\
\text { Force \& Transmit Electromotive Force } \\
\text { \& Convert plasma to gas (cathodes) }\end{array}$ & $\begin{array}{l}\text { Embed component/Multi-material } \\
\text { structures. Customized geometry }\end{array}$ & $\begin{array}{l}\text { Low TRL and materials development for embedded } \\
\text { components and multi-material structures. Material availability. }\end{array}$ & $\begin{array}{l}\text { Minimum feature size, } \\
\text { Surface roughness } \\
\text { Minimum overhang angle }\end{array}$ \\
\hline $\begin{array}{l}\text { Convert Electrical to Magnetic Energy \& } \\
\text { Collect electromotive force } \\
\text { (electromagnets/magnets) }\end{array}$ & $\begin{array}{l}\text { Embed component/Multi-material } \\
\text { structures/Customized geometry }\end{array}$ & $\begin{array}{l}\text { Low TRL and materials development for permanent magnets, } \\
\text { embedded components in the TU and multi-material structures. } \\
\text { AM electromagnets uncommon in space applications }\end{array}$ & Minimum feature size \\
\hline $\begin{array}{l}\text { Import Gas \& Guide gas (Fluid } \\
\text { management system) }\end{array}$ & $\begin{array}{l}\text { Embed component/ Customized } \\
\text { geometry }\end{array}$ & $\begin{array}{l}\text { Minimum hole diameter } \\
\text { Surface roughness } \\
\text { Minimum overhang angle } \\
\text { Powder evacuation (if powder bed is implemented) }\end{array}$ & $\begin{array}{l}\text { Minimum hole diameter } \\
\text { Surface roughness } \\
\text { Minimum overhang angle } \\
\text { Minimum wall thickness }\end{array}$ \\
\hline $\begin{array}{l}\text { Supply Gas (Fluid management system- } \\
\text { anode connection) }\end{array}$ & $\begin{array}{l}\text { Embed component/Multi-material } \\
\text { structures. }\end{array}$ & $\begin{array}{l}\text { Low TRL and materials development for multi-material } \\
\text { manufacturing of metal-ceramic connections }\end{array}$ & Not applicable \\
\hline $\begin{array}{l}\text { Convert Elect. Energy to Electromotive } \\
\text { Force (Anode) }\end{array}$ & $\begin{array}{l}\text { Embed component/Multi-material } \\
\text { structures/Customized geometry }\end{array}$ & $\begin{array}{l}\text { Low TRL and materials development for embedded } \\
\text { components and multi-material structures } \\
\text { Surface roughness }\end{array}$ & $\begin{array}{l}\text { Surface roughness } \\
\text { Minimum wall thickness } \\
\text { Minimum overhang angle }\end{array}$ \\
\hline $\begin{array}{l}\text { Guide Plasma } \\
\& \text { Increase linear velocity of plasma } \\
\text { (Grids) }\end{array}$ & $\begin{array}{l}\text { Embed component/Multi-material } \\
\text { structures/Customized geometry }\end{array}$ & $\begin{array}{l}\text { Low TRL and materials development for embedded } \\
\text { components and multi-material structures } \\
\text { Support structures if a grid is consolidated with the chamber }\end{array}$ & $\begin{array}{l}\text { Minimum feature size } \\
\text { Minimum thickness } \\
\text { Surface roughness }\end{array}$ \\
\hline
\end{tabular}

Figure 5 presents the constraints-based GIT concept, designed to be manufactured with metal powder bed AM technologies. This concept is an AM enabled annular thruster with one central cathode (1) for ion neutralization and one cathode and propellant inlet (2) for plasma generation (Patterson et al., 2012). The grids (3) can be manufactured with either molybdenum or titanium (Guo et al., 2019) and, as AM of alumina components is yet not fully (Aboulkhair et al., 2019) developed, the insulation between the grids (4) can be fabricated with AM technologies for ABS components (Kindberg, 2017). However, due to high-temperature requirements, the magnets require alumina insulation, which can be manufactured by traditional manufacturing methods. The GIT implements traditionally manufactured magnets arranged in 4 rings (5), two internal and two externals. In this case, small individual magnets are placed inside pockets in an AM stainless steel anode (6), the size of the pockets is restricted by the minimum manufacturable AM pocket size. A straight anode shape was preferred as inclined or curved surfaces can have poor surface finishing due to staircase effect. The GIT exterior carcass (7) is manufactured as a component separated from the chamber, in aluminium with a patterned wall for reducing component weight, its geometrical characteristics are restricted by minimum wall thickness and feature size achievable with aluminium.

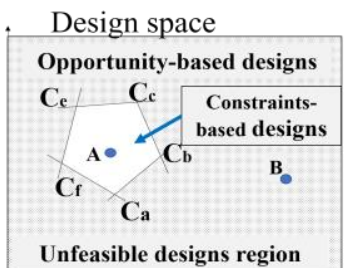

a)

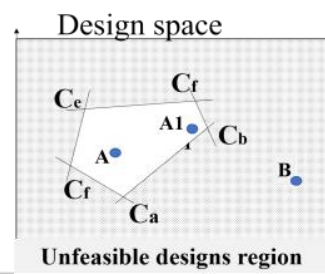

b)

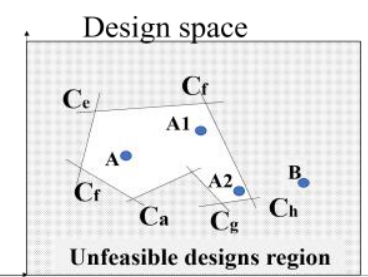

c)

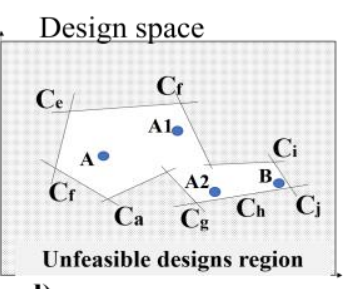

d)

Figure 5. Incremental constraint release 
Every AM GIT component was designed to avoid support structure generation. Moreover, due to low TRLs of cathode materials and the criticality of this component, it was not designed for AM.

\subsection{Concepts evaluation}

The main differences between the opportunity-based design and the constraint-based design are:

1. A larger number of consolidated components and fewer necessary assembly steps in the opportunity-driven design;

2. A broader implementation of AM technologies and design freedom in the opportunity-based design;

3. Lower TRL for most of the AM technologies implemented in the opportunity-based design.

Both concepts were evaluated by two designers with experience in AM and two designers of aerospace components. Because most of the product value is established in early design phases, the evaluation of design in this step is crucial for the designers (Audoux et al., 2018). The evaluation of concepts was conducted through informal meetings and short interviews. The evaluation criteria were focused on perceived performance, weight and volume reduction, design feasibility and development time. From this evaluation the most important points are highlighted below:

- The opportunity-based concept has a higher perceived performance, due to a rounder chamber shape and integrated components. Less number of components contribute to reduce failure rates. The constraints-based design presents some consolidated components, but its design is less innovative. Some of its features could be manufactured with other technologies but if the design is manufactured with AM it can reduce manufacturing time, reducing the number of operations to fabricate components.

- Some AM principles implemented in the opportunity-based concept have currently a low TRL that make them impossible to be manufactured today. However, they can be envisioned for future company development projects, as technologies such as multi-material structures or miniature internal channels are rapidly evolving. The opportunity-based concept is a new design for space manufacturers as well, therefore, to be considered for production it should go through extensive development and testing schemes which are nowadays non-standardized.

\section{Discussion}

In this study, the "Mapping of product functions with design principles" (Valjak et al., 2018), was implemented to develop two concepts of mini GIT. The used method do not consider manufacturing limitations and is oriented on removing cognitive barriers to creativity. The method was performed with a Hirtz-based function model and was used to develop the opportunity-based design. A constrained version of the same FM was used for the constraints-based design.

From the implementation of this FM technique, it was observed that as the definitions of functions and flows in Hirtz's vocabulary are rather abstract, therefore the creation of the function model with this vocabulary was ambiguous. For example, it is not established if electrons should be represented by "Electromotive Force" as energy flow or should they be represented with additional material flow as well.

Moreover, as the function model is highly abstract it does not include the means for fulfilling the functions (design solutions), the AM capabilities (which can be understood as function means) had to be documented in a morphological matrix. This fact presented challenges when accounting for functions that derive from specific design solutions (Such as "Hold magnets in place") this rendered the introduction of constraints in the model, impossible. For that reason, manufacturing constraints were not included in the function model but where included in the morphological matrix as well.

The benefits from the opportunity-based design include an extensive implementation of AM capabilities, suggesting a large design space and design freedom due to its strong emphasis in product functionality and performance. This qualities result in a compact and consolidated lightweight design, with reduced manufacturing time. The constraints-based design is feasible and manufacturable. Compared with current product designs (manufactured with traditional manufacturing techniques), it 
can reduce manufacturing time, reducing the number of operations to fabricate components. These qualities are due a strong emphasis during the application of the constraint-based method on AM manufacturability aspects.

The results of the comparison of the two designs suggest that, on one side, to develop the opportunitybased concept, a company should do large and time-consuming investments to raise the TRL levels of the AM capabilities implemented, incurring in expensive non-recurrent costs.

On the other side, the proposed constraints-based concept is rather similar to GIT manufactured with traditional technologies.

In this concept, the implementation of constraints restricted the design space to designs which are manufacturable nowadays or in a near future, compromising however, performance and product weight. The comparison between the opportunity-based and the constraints-based concepts further highlights the trade-offs that a company makes between the customer's desires for performance and the manufacturers expectations for cost-efficient feasible manufacturable components.

On the other side, releasing constraints frees the design space and provides designs that could be feasible in the future, after appropriate technology development strategies. The architecture of the constraints-based design is limited by current AM technologies albeit manufacturable. The opportunity-based design implements technologies which are not yet developed and constrain the design space in a way that render the design unfeasible, as presented in Figure 5.a.

However, not having a structured and precise way to distinguish which constraints must be released and which must not, can end up un long and costly technology development endeavours. Constraints representation can direct the attention to company capabilities that need to be improved or where future investment is needed. For instance, to manufacture a component with thinner AM walls, a company can consider purchasing more advanced AM machines or consider working with different materials. Moreover, as the manufacturer company is (most likely) not the same company that performs the technology development activities, an unprecise assessment of the technologies necessaries to develop a product can lead to the establishment of unrealistic technology roadmaps. A poor assessment of the constraints that need to be released to render a design feasible can misguide a company to plan a product development process too early or too late.

Constraints representation of current feasible (point A) and targeted unfeasible (point B) can support the creation of technology development roadmaps able to precisely identify a time (and perhaps investment) frame where different areas of AM technologies are going to be improved.

Constraints representation can also aid designers to establish intermediate profitable product architectures (A1 and A2 between A and B in Figure 5.b, c and d) that represent an incremental increase of the TRL necessary to reach point B. This incremental TRL development can be understood as an incremental constraints release that can support cost and development times of the product architectures in a technology road map.

As authors such as Conrow (2011) reported, previous attempts to relate technology roadmaps to cost and schedule planning are mostly subjective. The ability to determine a technology/architecture development path based on incremental constraints release, can be the first step towards analytic estimations of costs and development times of technology roadmaps. On the other hand, the case study is conducted on the example of AM for space applications. While the methodology for the development of the technology roadmaps can be used in other areas of AM application, the results of the case study are not transferrable. Further case studies using the same methodology should be conducted to generalise and validate the findings.

\section{Conclusion}

In this article a strategy for supporting the development of affordable and realistic technology roadmaps for additive manufacturing is proposed. This strategy proposes constraints modelling as a mean to highlight company capabilities that need to be improved, evidencing where future investments are needed. For this purpose, two concepts, an opportunity- and constraint- based concept, of a gridded ion thruster are developed. The development of both concepts is based on a Hirtz-based function modelling approach. While the opportunity-driven concept incorporates AM possibilities without considering technology limitations, thus creating an unfeasible design with current AM TRL, 
the constraint-based concept considers the limitations of current AM technology and present a feasible design. The comparison of the two designs suggests that, the opportunity-based concept has a higher perceived performance. However, to develop this concept, a company should do large and timeconsuming investments to raise the TRL levels of the AM capabilities implemented in this, incurring in expensive non-recurrent costs.

Constraints modelling can direct the attention to company capabilities that need to be improved or where future investment is needed in order to reduce AM limitations increasing the design space and enabling the design of products with higher performance. Constraints representation of current and feasible design and future (currently unfeasible) designs can support the creation of technology development roadmaps able to precisely identify areas of AM technologies that must be improved.

\section{Acknowledgements}

The authors gratefully acknowledge the financial support from VINOVA for funding provided to the project IDAG (2019-02502 Infrastructure for Digitalisation enabling industrialization of Additive manufacturing) that made possible this study.

\section{References}

Aboulkhair, N.T. et al. (2019), "3D printing of Aluminium alloys: Additive Manufacturing of Aluminium alloys using selective laser melting”, Progress in Materials Science, Vol. 106, p. 100578. https://doi.org/ 10.1016/j.pmatsci.2019.100578

Audoux, K. et al. (2018), "Selection method for multiple performance sevaluation during early design stages", Procedia CIRP, Vol. 70, pp. 204-210. https://doi.org/10.1016/j.procir.2018.03.295

Borgue O. et al. (2019), "Constraint Replacement-Based Design for Additive Manufacturing of Satellite Components: Ensuring Design Manufacturability through Tailored Test Artefacts”, Aerospace, Vol. 6 No. 11, p. 124. https://doi.org/10.3390/aerospace6110124

Boyard N. et al. (2013), "A design methodology for parts using additive manufacturing", Proceedings of the 6th International Conference on Advanced Research in Virtual and Rapid Prototyping (VRAP), Leiria, Portugal, October 1-5, 2013, CRC Press, Leira, pp. 399-404. https://doi.org/10.1201/b15961-74

Campbell, I., Bourell, D. and Gibson, I. (2012). "Additive manufacturing: rapid prototyping comes of age", Rapid Prototyping Journal, Vol. 18 No. 4, pp. 255-258. doi: https://doi.org/10.1108/13552541211231563

Conrow, E.H. (2011), "Estimating technology readiness level coefficients", Journal of Spacecraft and Rockets, Vol. 48 No. 1, pp. 146-152. https://doi.org/10.2514/1.46753

de Alcantara, D.P. and Martens, M.L. (2019), "Technology Roadmapping (TRM): a systematic review of the literature focusing on models", Technological Forecasting and Social Change, Vol. 138, pp. 127-138. https://doi.org/10.1016/j.techfore.2018.08.014

Diegel, O., Nordin, A. and Motte, D. (2019), A Practical Guide to Design for Additive Manufacturing, Springer, Singapore. https://doi.org/10.1007/978-981-13-8281-9

Gerdsri, N., Kongthon, A. and Vatananan, R.S. (2013), "Mapping the knowledge evolution and professional network in the field of technology roadmapping: a bibliometric analysis", Technology Analysis \& Strategic Management, Vol. 30 No. 4, pp. 403-422. https://doi.org/10.1080/09537325.2013.774350

Guo, N. et al. (2019), "3D printing of ion optics for electric propulsion”, Frontiers in Physics, Vol. 6 No. 145 , pp. 1-12. https://doi.org/10.3389/fphy.2018.00145

Hirtz, J. et al. (2002), "A functional basis for engineering design: Reconciling and evolving previous efforts", Research in Engineering Design, Vol. 13 No. 2, pp. 65-82. https://doi.org/10.1007/s00163-001-0008-3

Hopping, E.P. and Xu, K.G. (2017), "Design and Testing of a Hall Effect Thruster with 3D Printed Channel and Propellant Distributor", 35th International Electric Propulsion Conference, p. IEPC-2017-119

Kindberg, P. (2017), Development of a miniature Gridded ion thruster [Master Thesis], Luleå University of Technology.

Lai, C., Xu, L. and Shang, J. (2019), “Optimal planning of technology roadmap under uncertainty”, Journal of the Operational Research Society, pp. 1-13. https://doi.org/10.1080/01605682.2019.1581406

Lu, S.C. and Liu, A. (2011), "Subjectivity and objectivity in design decisions", CIRP annals, Vol. 60 No. 1, pp. 161-164.

Nano Dimension (2019), Rapid prototyping of electromagnets with 3D printing. [online] Nano Dimension. Available at: https://www.nano-di.com/3d-printing-applications-for-electromagnets (accessed 25.10.2019). 
Öhrwall Rönnbäck, A.B. and Isaksson, O. (2018), "Product development challenges for space subsystems manufacturers", Proceedings of the DESIGN 2018 15th International Design Conference, Dubrovnik, Croatia, The Design Society, pp. 1937-1944. https://doi.org/10.21278/idc.2018.0534

Patterson, M. et al. (2012), "Annular-geometry ion engine: Concept, development status, and preliminary performance", 48th AIAA/ASME/SAE/ASEE Joint Propulsion Conference \& Exhibit, p. 3798.

Patterson, A. and Allison, J. (2019), "Generation and mapping of minimally-restrictive manufacturability constraints for mechanical design problems", Proceedings of the 24th Design for Manufacturing and the Life Cycle Conference (DFMLC)-ASME IDETC/CIE, 18-21 August 2019, Anaheim, CA, USA, pp. 1-12.

Pahl, G. et al. (2007), Engineering Design, edited by Wallace, K. and Blessing, L., Third Edit., Springer, London. https://doi.org/10.1007/978-1-84628-319-2

Sarfaraz, M., Sauser, B.J. and Bauer, E.W. (2012), "Using System Architecture Maturity Artifacts to Improve Technology Maturity Assessment”, Procedia Computer Science, Vol. 8, pp. 165-170. https://doi.org/ 10.1016/j.procs.2012.01.034

Thompson, M.K. et al. (2016), "Design for Additive Manufacturing: Trends, opportunities, considerations, and constraints", CIRP Annals-Manufacturing Technology, Vol. 65 No. 2, pp. 737-760. https://doi.org/10. 1016/j.cirp.2016.05.004

Umeda, Y., Takeda, H. and Tomiyama, T. (1990), "Function, Behaviour and Structure", Applications of artificial intelligence in engineering, Vol. V No. 1, pp. 177-194.

Valjak, F., Bojčetić, N. and Lukić, M. (2018), "Design for Additive Manufacturing: Mapping of Product Functions", Proceedings of the DESIGN 2018 15th International Design Conference, 21-24 May 2018, Dubrovnik, Croatia, The Design Society, Dubrovnik, Croatia, pp. 1369-1380. http://doi.org/10.21278/idc.2018.0364

Viola, N. et al. (2020), "Technology RoadmappIng Strategy, TRIS: methodology and tool for Technology Roadmaps for hypersonic and re-entry space transportation systems". Acta Astronautica.

Weilkiens, T. (2007), Systems engineering with SysML/UML: Modelling, analysis, design, Morgan Kaufmann Publishers Inc., San Francisco.

Williamson, R. and Beasley, J. (2011), "Automotive technology and manufacturing readiness levels: a guide to recognised stages of development within the automotive industry”, Automotive Council, URN11/672. 